\title{
Subject access to periodicals: A Main-Mac combo
}

\author{
By Constance L. Foster
}

Serials Supervisor

Western Kentucky University

As a serials librarian and supervisor, I find my few voluntary hours each week at the Ready Reference desk a truly humble experience. My command of serials lingo and skills as a supervisor matter little to the patron who needs a quick answer to yesterday's assignment or who rushes in with only ten minutes before she has to give a speech in class. Questions such as "Which journals have articles about drugs?-I don't need to see them, just list them," or "I have to look at three music journals—where are they?" hurriedly bring to my mind images of OPACs, COM catalogs, PCs, CDROMs, and printouts for possible access to these frantic queries. Almost instantaneously, however, I reach calmly for the WKU Libraries Subject Guide to Current Periodicals, a modest twenty-eight page document in a plastic report cover and turn to the subject and periodicals listing in question. This printed guide is the result of my reference service, yet it is also proving useful for other purposes. Such a subject guide listing of current periodicals, as an additional access point for information in small and medium-sized libraries, is a very feasible item to produce once the initial database has been created.

To assimilate 2,550 titles into subject areas was possible primarily because of our online serials check-in and management system at Western Kentucky University Libraries. Communicating with a mainframe computer thousands of miles away, this flexible system allows for immediate input and updating of serial records and reports generated on several sortable fields such as fund, holdings, routing, call number, marking, and subject. When we first input all of our check-in information six years ago, we also made the decision to utilize as many fields as possible and to select the proper Library of Congress classification code for all serials. For the uncataloged periodicals, we assigned the LC subject closest to the nature of that title (in many cases the automated system had a suggested code); for the cataloged serials we used the call number assigned through our normal cataloging procedures. Each new title entered on the system always gets a subject code at the time the order is placed and the screen is set up, with allowance for possible revision.
A printout by subject sort of all titles in our database served as the working copy for the beginning of this project. With this hard copy at hand we eliminated continuations, memberships, departmental orders, and other extraneous titles that did not fit the current periodicals scope for our main library, Science Library, Kentucky Library, and Educational Resources Center. The first edition of the guide did not include newspapers, but they were added in a later edition.

We then scrutinized the assigned LC headings in relation to our university's current catalog of department names and the course bulletin of class offerings to refine headings for local use as needed, e.g., History: Kentucky; Education: Higher; Institution Administration (for Hotel/Restaurant Management); Communications and Broadcasting. This process took approximately forty hours of staff time (one person) with consultations and revisions by the serials supervisor.

With a list of seventy-nine subject headings for 2,550 titles, we used a Macintosh Plus at the Faculty Media Center and Microsoft Works 1.0 to alphabetize the titles within each subject. A separate export file was needed for each subject in order for the whole document to be transported into Ready, Set, Go! 4.0a for the final layout and printing in a two-column format.

This data input involved two people (one staff, one supervisor) for about thirty-seven hours, or a three-week period, and an additional three hours to move all the files into RSG. Once this phase was completed, however, the major time-consuming part was done, the database created. To keep track of new titles, deletions through cessations or cancellations, and changes, the serials supervisor keeps a "working copy" of the guide at arm's length in order to record each change for the next edition, since all serial entries or changes pass over her desk sooner or later!

For printing the final version we relied on the university's print shop and later the copy center. We first printed one hundred copies, fourteen pages (front/back), plus a red-topped cover page that is used for all WKU Libraries guides and information sheets. We distributed the guide to 
library faculty, departmental liaisons, department heads, deans, and directors. As additional requests come, the number of copies increases but not significantly. For 1988 the printing cost was $\$ 74.00$ and another $\$ 14.00$ for the report covers. These covers seem best suited for the narrow margins, eliminate holes and spiral bindings that get caught on surrounding materials. Since the present software rearranges the total document each time a line is deleted or added, the guide is completely reprinted with each revision.

Besides referring to the guide as another access point for serials information, many library faculty find it useful in compiling statistics for reports requiring number of titles held in a specific area like "Reading," or "Economics." We send a copy to the local public library and have had requests from area community colleges and universities for use in interlibrary lending and referrals. The collection development coordinator and our subject reference librarians find this resource beneficial when they assess areas of growth and in preparing bibliographies. A copy of the "Psychology" titles is placed on the index table that holds Psychological Abstracts to identify which journals we have. As with most abbreviated resources, we have a "disclaimer" to consult the WKU Serials List on microfiche for completed holdings and locations for these titles.
Once a resource like this appears, suggestions for enhancements emerge through memos, conversations, and self-imposed ideas! The most requested addition at this point is a straight alphabetical listing of all current titles; to that is added a request for abbreviated holdings. Next might come an index of titles to subjects, possibly followed by more cross-listings or multiple listings of titles that are interdisciplinary-not to mention the inclusion of newsletters and the desire by some for all serials (cataloged or not)! So interest is alive as evidenced by such suggestions, and we do weigh each carefully against our present method of input and time for what appear to be additional databases.

In our high-tech library world, surrounded by coaxial cables and the bleeps of PCs, a printed resource as a ready reference tool remains a viable addition to a library's collection. It can at least guarantee quick response time and absolutely no down time or temporary break in communications. As Lynn Smith observes, "All material in the library should be as approachable from as many angles as possible." This subject guide offers an additional access to information about periodicals and can supplement the variety of formats a library already offers to its users.

${ }^{1}$ Lynn S. Smith, A Practical Approach to Serials Cataloging (Greenwich, Conn.: JAI Press, 1978), 174.

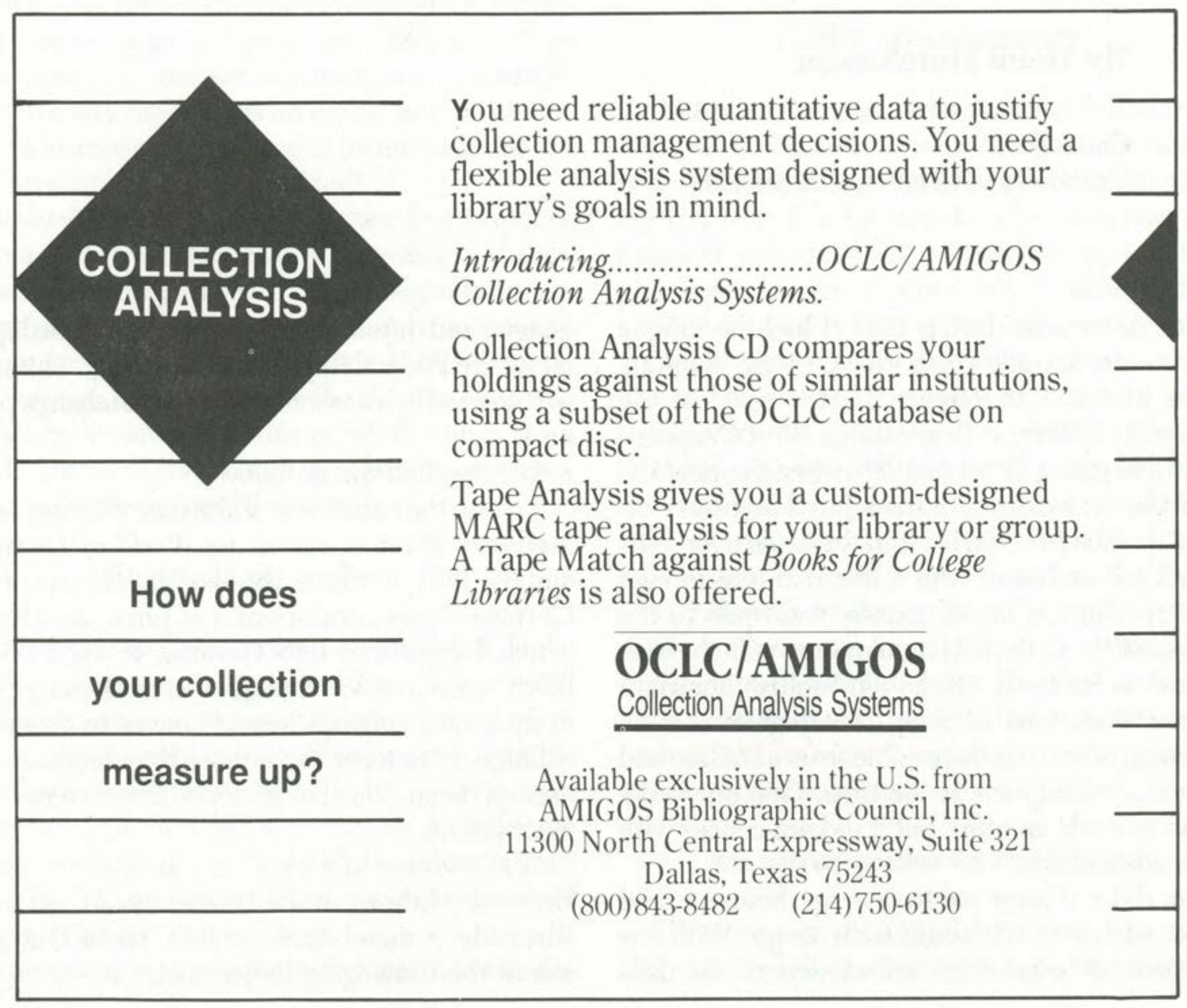

